Rüdiger Südhoff · Die intertextuelle Sinnkonstitution im Bildungsroman der Weimarer Klassik 
Rüdiger Südhoff

\section{Die intertextuelle Sinnkonstitution im Bildungsroman der Weimarer Klassik}

Poetologische Paradigmen der Aufklärungsliteratur in Goethes "Lehrjahren"

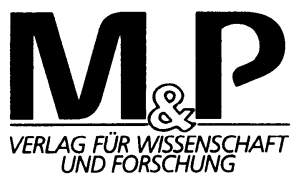


Dissertation zur Erlangung des Grades des Doktors der Philosophie beim Fachbereich Sprachwissenschaften der Universität Hamburg, vorgelegt von Rüdiger Südhoff aus München. Als Dissertation angenommen vom Fachbereich der Sprachwissenschaften der Universität Hamburg.

Die Deutsche Bibliothek - CIP-Einheitsaufnahme

\section{Südhoff, Rüdiger:}

Die intertextuelle Sinnkonstitution im Bildungsroman der

Weimarer Klassik : poetologische Paradigmen der

Aufklänungsliteratur in Goethes "Lehrjahren" / Rüdiger

Südhoff. - Stuttgart : $M$ und $P$, Verl. für Wiss. und Forschung,

1994

Zugl.: Hamburg, Univ., Diss., 1991

ISBN 978-3-476-45050-0

ISBN 978-3-476-45050-0

ISBN 978-3-476-04207-1 (eBook)

DOI 10.1007/978-3-476-04207-1

Dieses Werk ist einschließlich aller seiner Teile geschützt. Jede Verwertung außerhalb der engen Grenzen des Urheberrechtsgesetzes ist ohne Zustimmung des Verlages unzulässig und strafbar. Das gilt insbesondere für Vervielfältigungen, Übersetzungen, Mikroverfilmungen und Einspeicherung in elektronischen Systemen.

M \& P Verlag für Wissenschaft und Forschung ein Verlag der J.B.Metzlerschen Verlagsbuchhandlung und Carl Emst Poeschel Verlag GmbH in Stuttgart

(C) 1994 Springer-Verlag GmbH Deutschland

Ursprünglich erschienen bei J. B. Metzlersche Verlagbuchhandlung und Carl Ernst Poeschel Verlag GmbH in Stuttgart 1994 
Danken möchte ich Prof. Dr. K.R. Mandelkow und Prof. Dr. G. Dammann, E. Südhoff und C. Löhden für die hilfreichen Anregungen und Ratschläge, die mir die Verwirklichung dieser Arbeit ermöglichten. 


\section{Inhaltsverzeichnis}

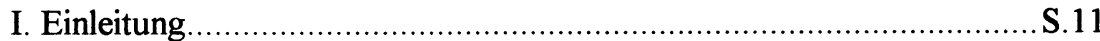

II. Wilhelm Meister, der Dichter der höheren Poesie

1. Der Dichter im Kontext der poetischen Wort- und Bildfelder

2. Die dynamische Manier des musikalischen Dichters

3. Gesang und Lied, die erhabene und die sanftere Gattung der höheren Poesie

III. Die Wiederherstellung der anakreontischen Requisiten in der Lieddichtung

1. Die Zauberei der Liebe als perspektivische Magie des blöden Schäfers

2. Der Held im Interieur des epischen Scherzgedichtes

3. Das parodistische Kontrastverhältnis zwischen erotischer und hoher Liebesauffassung....

4. Die Ersetzung der Distanzhaltung des Witzes durch die Ausdruckshaltung des Herzens

5. Die Abgrenzung der wahren Leidenschaft von den nur fiktiven Erlebnissen.

6. Die erotische Krise im Licht der Lieddichtung Klopstocks

IV. Wilhelm Meister als der Dichter der heiligen Poesie:

Der Brief an Mariane

1. Sendungsbewußtsein und Vision des poeta vates

2. Der musikalische Stil des Briefes

3. Der dissonante Schlußakkord

4. Die profanen Triebfedern ........................................................... 92

5. Der Brief als lyrische Romaneinlage .............................................. 96 
V. Das lyrisch-musikalische Finale: Der furchtbare Absturz

1. Die Einheit von Rollen- und Erzählerrede im Wechselgesang ........... S.101

2. Das Formprinzip der Ironie ....................................................... 103

3. Der Spiritualismus der Lieddichtung und der erotisch-scherzhafte

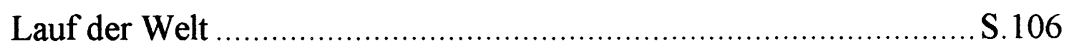

4. Das Erhabene in der Gestalt des Gemeinen ................................... S. 112

5. Aufschwung und Absturz, das Bewegungsgesetz

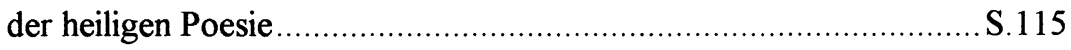

VI. Der Harfner, der heilige Dichter als heilloser Sänger ..................... S. 122

VII. Das bürgerliche Trauerspiel im ersten Buch der Lehrjahre

1. Die Melina-Epiosde, ein bürgerliches Trauerspiel ............................ S.131

2. Die Zerrüttung des bürgerlichen Trauerspiels .................................. 135

3. Die Esoterik der Melina-Episode .................................................. 138

4. Die Funktion der Episode in der 'Sendung' ..................................... 142

5. Der dramatisierte Romanbeginn in den 'Lehrjahren' ........................ S. 144

6. Der Funktionswandel der Episode:

Die Unähnlichkeit der Schicksale .................................................. S.148

7. Das Trauerspiel des 'höheren' Bürgers in seiner Abgrenzung vom Trauerspiel des Philistertums der deutschen Provinz ................ S. 150

VIII. Die Lösung der inneren Konflikte im rührenden Lustspiel

1. Die Mischung und Entheroisierung des Charakters.......................... S. 155

2. Der soziale Status des gemischten Charakters ................................. 160

3. Parallelen zum Ehre-Liebe-Konflikt in Lessings

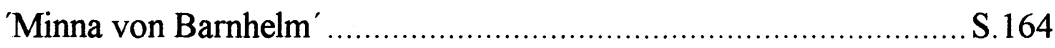

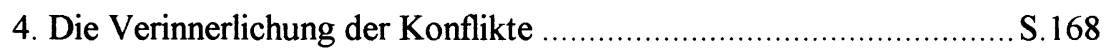

5. Die Konfliktlösung im Zeichen der Katharsis.................................. S.173 
IX. Die Einbeziehung der höheren Standespersonen in den Bezirk der gesellschaftskritischen Typenkomödie

1. Die moralisch-empfindsame Kritik der großen Welt S. 179

2. Die satirische Darstellung des hochadeligen Gönners S. 187

3. Die Kritik des Künstlers am Hofe S. 193

X. Die Einflechtung des Tragischen in den Roman

1. Die Kritik der Mitleidsethik S. 198

2. Wilhelm Meister vor dem strengen Gericht der 'Emilia Galotti' S.201

3. Die immanente Kritik des Bildungsromans S.207

XI. Literaturverzeichnis S. 210 